\title{
XXXIX. Thorium radiation
}

\section{R. B. Owens E.E.}

To cite this article: R. B. Owens E.E. (1899) XXXIX. Thorium radiation, Philosophical Magazine Series 5, 48:293, 360-387, DOI: 10.1080/14786449908621345

To link to this article: http://dx.doi.org/10.1080/14786449908621345

$$
\text { 曲 Published online: } 08 \text { May } 2009 .
$$

Submit your article to this journal $\sqsubset$

山 Article views: 12

Q View related articles $\sqsubset$ 
placing this pair with their principal axes at $45^{\circ}$ to the polarizer and rotating the analyser, the field appeared white and of uniform intensity, the variation being very much less than with a true $1 / 4 \lambda$ plate of mica or of selenite, but not so perfect as was obtained with the Fresnel rhomb. Fresnel's formula gives for crown-glass a difference of phase of $1 / 10 \lambda$ between the extreme red and violet rays when the relative retardation is one $\lambda$.

When these combinations were examined in divergent light with the polarizer and analyser either crossed or parallel, the isochromatic lines in the centre of the field were nearly colourless, and the neutral hyperbolic line became pink when the line of the optic axes was not parallel or perpendicular to the principal plane of the polarizer ; both sets of fringes, however, had the same general form as when mica was used alone.

Similar results were obtained with mica and quartz, this latter combination not giving quite as good compensation as the former.

Achromatic wedges might also be obtained by a similar combination, the proper ratio of the orders being maintained over the entire length of the wave. Combinations of such systems might also be used as an achromatic compensator in a similar way to that of Babinet's compensator, the distance apart of the bands within the field being given in the equations already discussed.

With systems of more than two crystals better achromatism would be possible, but the mechanical difficulties would be serious. Over parts of the spectrum very close achromatism may be obtained with the above crystals.

Further observations on other crystals may reveal better combinations than already examined. A careful study of the distribution of the bands of different erystals in a normal spectrum would furnish more definite data than the observations here given with a prismatic spectrum.

Physical Laboratory, University of Nebraska, Lincoln, July 22, 1899.

XXXIX. Thorium Radiation. By R. B. Owens, E.E., Tyndall Fellow, Columbic University, New York; Macdonald Professor of Electrical Engineering, McGill University, Montreal*.

$7 \mathrm{HE}$ nature of the radiations emitted by uranium and its 1 compounds was studied in 1896-97 by its discoverer

* Communicated by Prof. J. J. Thomson, F.R.S. 
Becquerel *, and more elaborately by Rutherford $\dagger$ two years later. In May 1898 Schmidt $\ddagger$ announced that thorium and its salts gave off a similar radiation. Briefly it was found that such radiations had the power of penetrating considerable thicknesses of metals and other opaque substances, of acting on a photographic plate, of ionizing the gas in the neighbourhood of the active material, and in general possessed properties similar to those of Röntgen rays.

Rutherford investigated very fully the conductivity produced in different gases by uranium radiation, the absorption of the radiation by different substances, the relative intensity of the radiations emitted by different uranium salts, the velocity and rate of recombination of the ions produced in the surrounding gas, \&c., and was enabled to very clearly interpret his results on Thomson's ionization theory of gas discharge. He also found the radiations to be complex, consisting of at least two different types, one being readily absorbed by thin sheets of metal foil or layers of gas, and the other, a more penetrating kind, passing through ten to twenty times the same thickness of foil with but a few per cent. diminution of intensity. $\mathrm{He}$ also found in comparing the radiations emitted by the different compounds of uranium that the amount of the more penetrating kind as a per cent. of the whole varied with the kind of salt used and with the thickness of the radiating layer for each particular salt.

When the same method of analysis is used, namely, the screening effect of thin layers of certain metals, similar results may be obtained for thorium, as will be shown later, but there are indicutions that thorium radiation is not confined to so few distinct types, if indeed the number is limited. Certainly it would be difficult to formulate a theory for the production of such rays which would account for only a particular number of kinds being produced. If $x$-rays and the radiations from uranium, thorium, polonium, \&c. are disturbances in the rther occasioned by the internal motion of certain constituent parts of the atom, as has been suggested, it might be expected that such disturbances would shade off with some degree of regularity from a more intense to a less intense kind, and such stems to be the case with thorium.

The principal points in regard to thorium radiation treated of below may be classed under the following heads :-

1. Conditions affecting the constancy of the radiation.

2. The relation between current and electromotive force.

* Comptes Rendus, 1896-97. † Phil, Mag., Jan. 1899.

† Wied. Annal., May 1898 . 
3. Comparison of radiations from different salts.

4. Types of radiation.

5. Selective absorption.

6. Effect of suspended particles in the path of the conduction-current.

7. Variation of conduction-current with pressure of gas.

8. Absorption of radiations in air.

The particular thorium salts employed as a source of radiation were the oxide, sulphate, and nitrate. The method used for comparing the intensities of the radiations under different conditions was similar to that of Rutherford*.

A layer of the active material was spread uniformly over a small platinum plate resting on a larger brass one, the whole being covered, except the surface of the active material, with a heavy lead sheet to cut off stray radiations. An insulated parallel brass plate held at a suitable distance was connected to one pair of quadrants of a sensitive electrometer, the other pair of quadrants being permanently to earth. By means of a battery of small lead cells the lower plate could be maintained at different constant potentials.

When the quadrants of the electrometer were separated the top plate gradually acquired the potential of the lower one, and the rate of movement of the electrometer needle was taken as a measure of the current through the gas. The gradual charging of the top plate was due to the movement under the action of the applied electromotive force of the ions produced throughout the volume of the gas by the radiation absorbed by it.

1. Conditions affecting the Constancy of the Radiation.-The apparatus used in obtaining the relations of current and electromotive force, in comparing and analysing radiations, and in investigating the effect of suspended particles in the path of the conduction current, is shown in fig. $1 . B_{1}$ is an insulated brass plate on which rests the platinum plate $P$. On the platinum plate is spread the active material. Over the whole is the lead sheet $\mathrm{L}$, with its centre cut away, exposing an area of salt of $25 \mathrm{sq}$. cm. $B_{2}$ is an insulated plate with $a$ vertical movement and connected to the electrometer E. Both plates are enclosed in a metal box A, fitted with a door on one side to admit the plates. Placing a thick layer of thorium salt (about $1 \mathrm{~mm}$.) on $\mathrm{P}$, charging the lower plate to 95 volts and separating the quadrants very shortly after olosing the door of the surrounding box, the rate of leak was found to gradually increase but finally to reach a constant

* Phil. Mag., Jan. 1899. 
maximum value. If some time was allowed to elapse between placing the oxide in position and taking the observations the conduction current showed no increase with time. A sample

Fig. 1.

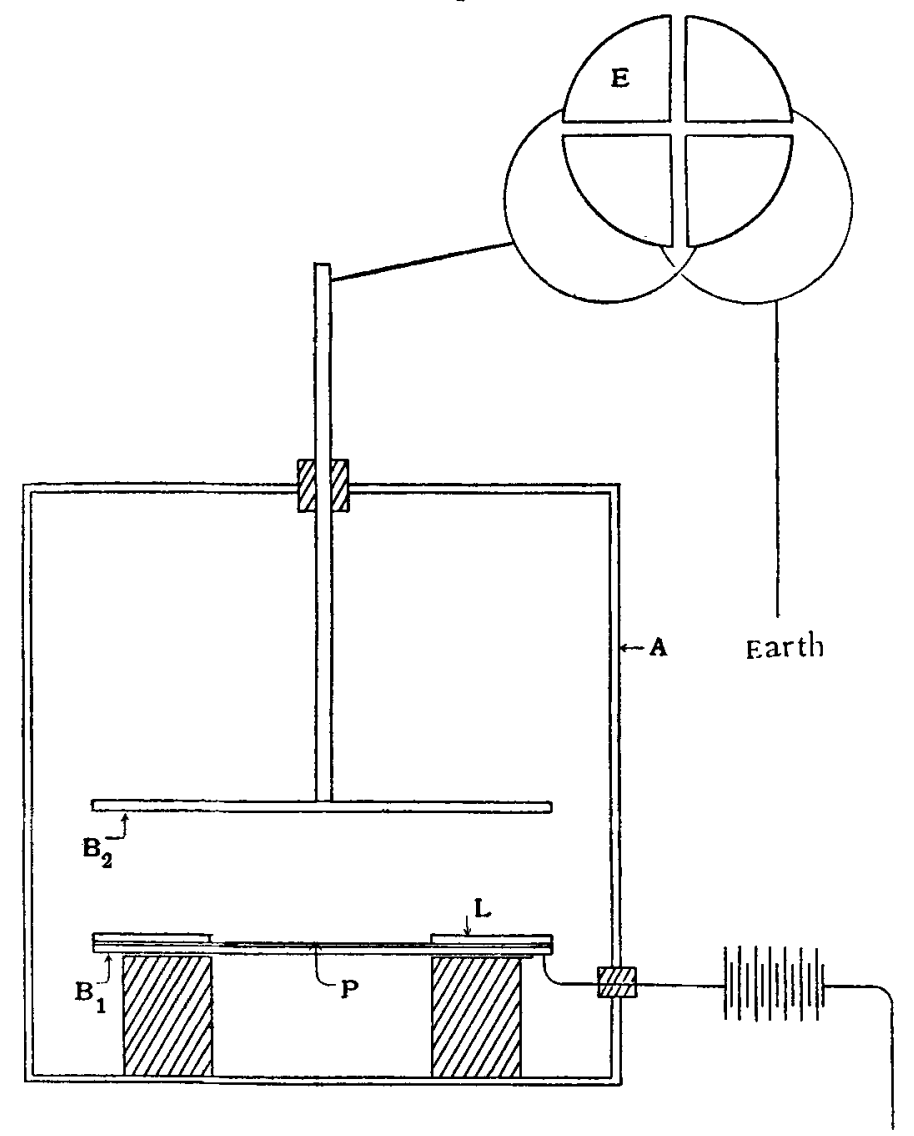

Earth

set of observations for thorium oxide under the first conditions is as follows:-

Plates $5 \mathrm{~cm}$. apart. Lower plate 95 volts + .

Time of 800 div. in sec.

$17 \cdot 4$ 1st observation.

$15 \cdot 6$ 2nd ,

$12 \cdot 6$ 3rd "

$12 \cdot 6$ 4th " 
Similarly for the nitrate:

Plates $5 \mathrm{~cm}$. apart. Lower plate 95 volts + .

Time of 100 div. in sec.

$65 \cdot 0$ 1st observation.

$63 \cdot 6 \quad$ 2nd

$6 \% \cdot 0 \quad 3$ rd

$62 \cdot 2 \quad 4$ th

",

"

,9

constant.

and for the sulphate :

Plates $5 \mathrm{~cm}$. apart. Lower plate 95 volts + .

Time of 100 div. in sec.

$61 \cdot 0$ 1st observation.

$60 \cdot 2$ 2nd

$58 \cdot 6$ 3rd

$58 \cdot 0$ - 4 "

$58 \cdot 0$ 4th,$\quad$ constant.

This time-effect is very marked with the oxide, and small and nearly equal for the nitrate and sulphate. When thin layers of the active material formed by sifting a little of the salt through a fine wire gauze were used, the effect was comparatively small, even with the oxide.

As the only apparent effect of waiting some minutes after placing the active material in position before taking observations was to allow the air in the box to come to a steady state, the effect of air-currents through the box was naturally suggested.

To investigate the effect of air-currents, a small box similar to that shown in fig. 1 was used, but made air-tight. In each of two opposite sides small tubes were fitted above the active material. By means of an air-pump or bellows currents of air of different velocities could be passed through the box. Then by inserting plugs of glass wool, vessels containing water, drying-mixtures, and other materials before the inlet tube, the effect of dust-particles, moisture, \&c. could be studied. A thick layer of thorium oxide was placed on the lower plate and charged to 95 volts positive.

After allowing time for the air in the box to become quiet, the conduction-current was repeatedly measured and found to be constant. Take this steady eurrent as 100 . A waterpump was then used to draw air through the apparatus at a fairly rapid and constant rate. The conduction-current fell to 33 .

The air was next made to bubble through a vessel of water before passing into the apparatus, but the conduction-current 
was found to be practically the same as when air was drawn directly from the room.

When a large tube of $\mathrm{P}_{2} \mathrm{O}_{5}$ was placed before the inlet pipe, the pump being in operation, the current increased to 36 . When a plug of glass wool was added, the value of the current became 37 .

We thus see that scarcely any difference is noticeable between moist air, dry air, and air free from dust. Indeed, the small increase of current actually observed may easily be accounted for by the diminished pressure and velocity of the gas in the vessel occasioned by placing the drying-mixture and wool plug before the inlet tube. The oxide was then covered with a layer of common writing-paper and the conduction-current measured, with and without the pump in operation; in the former case the current was about one third of its value in the latter.

Layers of thin aluminium foil were then substituted for the paper; with one layer of foil the current with pump on was 58 per cent. of current when air in vessel was at rest, with two layers 69 per cent., and with three layers 75 per cent.

The effect is thus seen to be diminished as the surface of the oxide is better protected from air-currents. The protection, however, was probably only partial, as both the paper and foil were no doubt more or less porous.

On covering the oxide with a mica sheet the actual conduction-current was greatly diminished, but remained practically constant whether the air in vessel was at rest or in motion.

Using a thin layer of oxide unprotected with paper or foil, the current with pump on was 80 per cent. of the current when the air was at rest, indicating that the radiations from thin layers are much less susceptible to air-currents than those from thick ones, or at least that the effect is closely related to the thickness of the layer. Using a thick layer of the sul. phate the diminution of current when the pump was operated was about 15 per cent., and with the nitrate practically the same, both much less than with the oxide.

Substituting uranium oxide for the thorium salts no diminution in the conduction-current was observable when the pump was in action.

With thorium salts the same general effects of air-currents were observed as different voltages were applied to the lower plate, as also was the case when the distance between the plates was varied. When oxygen and coal-gas were passed through the apparatus instead of air, a similar diminution of the con: duction-current when the gases were in motion was observed. 
When the air in the vessel was not drawn through but was simply agitated by a set of vanes attached to a vertical shaft fitting tightly through the upper cover and operated by a small motor, the side outlets being closed, the conduction-current actually increased with the speed of the vanes, showing that a mere motion of the air is not sufficient, but that it must be removed from the vessel to decrease the value of the current. While the experiments tried are not conclusive, they show that the effect depends on the actual passage of gas through the box, the thickness of the radiating layer, the nature of the salt used, and the degree of its protection, and so indicate that the cause, whatever it is, lies close to the surfuce of the active material. It is possible that some intense type of radiation coming from the body of a thick layer of certain salts changes the nature of their surfaces, forming in the neighbourhood a more active material which if removed from the containing vessel diminishes the amount of ionization produced.

All the observations recorded below were taken after the conduction-current had come to a steady value.

2. The Relation between Current and Electromotive Force. -The explanation of the general form of the curves showing the relation between current and electromotive force in ionized gases was pointed out by Thomson and Rutherford * in 1896 . For gas exposed to uranium radiation the relation was investigated the following year by Becquerel $t$ and de Smolan and Beattie $\ddagger$, and again in 1899 by Rutherford $\S$.

Using potentials less than a volt with plates close together, the latter found the conduction-current to vary with the sign of the lower plate, and to have a certain small constant value when no external electromotive force was acting, this being probable due to the contact-difference of potential between the uranium salt and the plate upon which it rested, and also to the ditferent velocity with which the positive and negative carriers diffuse. For large electromotive forces no appreciable difference in value of the current was observed whether the uranium was charged negatively or positively.

In the March number of the Phil. Mag. for this year Professor J. J. Thomson has given a general expression for the relation of the current and potential-difference between two parallel plates bounding a volume of ionized gas. His final equation is of the form

$$
\mathrm{V}=\mathrm{A} i^{2}+\mathrm{B} i
$$

* Phil. Mag. Nov, 1896.

$\ddagger$ Phil. Mag. p. 418 (1897).

† Comptes Rendus, pp. 438, 800 (1897).

\$ Phil. Mag., Jan, 1899. 
where $\mathrm{V}$ is the potential-difference between the plates and $i$ the current, and takes into account the variation of electric intensity between the plates.

In the experiments to determine the saturation curves for air ionized by thorium radiations, both the apparatus shown in fig. 1 and that shown in fig. 8, to be described later, were used. Very small voltages were not tried.

With large voltages the conduction-current was independent of the sign of the lower plate, corresponding in this regard to uranium.

Both the distances between the plates and the density of the gas were varied. For a given air-pressure the voltage required to carry the saturation curre over the "knee" was found to vary with the distance between the plates, and when the plates were maintained at a constant distance the voltage for the same purpose varied with the pressure of the gas, being much more as the gas pressure increased. The same general shape of curves was obtained when the surface of the salt was covered with a thin layer of aluminium foil as when the foil was removed.

Table I. shows how the current varied with the voltage, using a thick layer of thorium oxide covered with two layers of thin aluminium foil, the plates being 5 centim. apart. The results are expressed graphically in fig. 2 (p. 368).

\section{Table I.}

Thorium Oxide. Thick layer.

Saturation Curve.

Plates $5 \mathrm{~cm}$. apart. Two layers of Aluminium foil over active material.

\begin{tabular}{|c|c|c|}
\hline Volts. & Time of 100 div. in sec. & Current. \\
\hline 285 & $11 \cdot 3$ & $100 \cdot 0$ \\
185 & $11 \cdot 9$ & $95 \cdot 0$ \\
95 & $13 \cdot 0$ & $87 \cdot 0$ \\
$54 \cdot 5$ & $13 \cdot 9$ & $81 \cdot 0$ \\
$32 \cdot 7$ & $14 \cdot 9$ & $76 \cdot 0$ \\
$21 \cdot 8$ & $15 \cdot 9$ & $71 \cdot 0$ \\
$10 \cdot 9$ & $18 \cdot 6$ & $61 \cdot 0$ \\
$5 \cdot 5$ & $24 \cdot 8$ & $45 \cdot 0$ \\
$3 \cdot 3$ & $35 \cdot 0$ & $32 \cdot 0$ \\
$2 \cdot 2$ & $48 \cdot 0$ & $24 \cdot 0$ \\
$1 \cdot 1$ & $72 \cdot 0$ & $16 \cdot 0$ \\
\hline
\end{tabular}


3. Comparison of the Radiations from different Salts.Layers of the oxide, nitrate, and sulphate 5 centim. square, and very approximately $1.3 \mathrm{millim}$. thick, were placed in succession on the lower of two parallel brass plates 5 centim. apart. Each was charged to the same constant potential, 95 volts,

Fig. 2.--Saturation Curve.

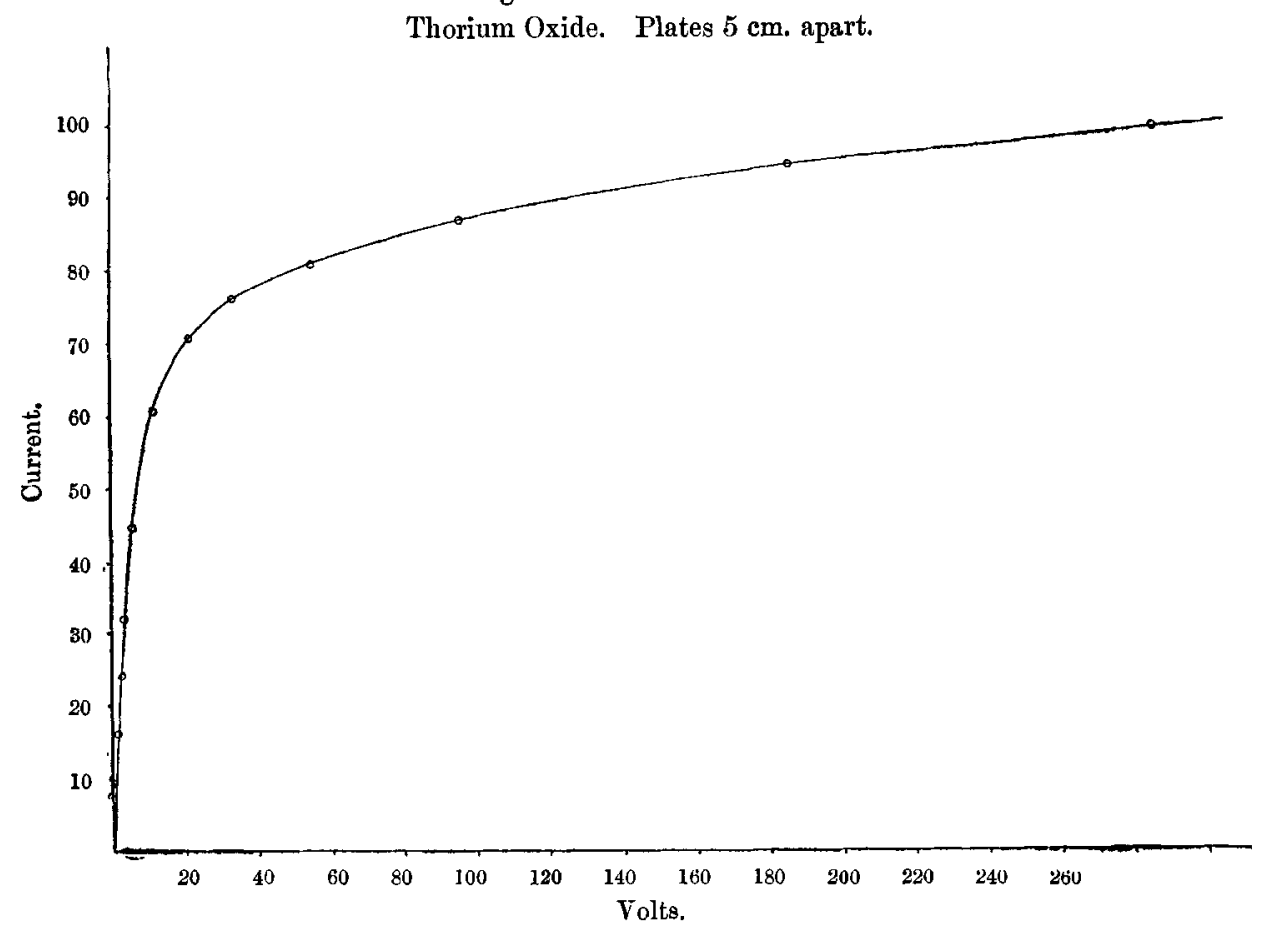

and the steady conduction-current measured. The results were as follows, where the current produced by the oxide is arbitrarily taken as 100 :-

$$
\begin{aligned}
& \text { Thorium oxide . . . } 100 \\
& \text { Thorium nitrate. . . } 18.5 \\
& \text { Thorium sulphate . . } 17.5
\end{aligned}
$$

We see that the oxide is about six times as active as either the nitrate or sulphate, the latter two are of approximately equal activity. The degree of purity of the salts was not determined.

4. Types of Radiation.-Röntgen rays are known to be of a complex nature, and Rutherford, as before stated, has found 
that the radiations from uranium salts are also complex, consisting mainly of two kinds, one much more penetrating than the other.

For investigating the nature of thorium radiations the method employed by Rutherford was used.

A layer of thorium salt was placed on the lower plate, shown in fig. 1 , charged to a potential of 95 volts, and the conduction-current measured.

Successive layers of foil were then placed over the salt and the current measured for each additional layer. Table II. gives the result for a thick layer of thorium oxide screened by successive layers of aluminium foil, each approximately .0008 centim. thick. The conduction-current with no foil over the active material is taken as 100 .

'TABLE II.

Thorium Oxide. Thick layer.

Screening effect of thin Aluminium foil.

Plates $5 \mathrm{~cm}$. apart. Lower plate 95 volts + .

\begin{tabular}{|c|c|c|}
\hline Liayers of foil. & Time of 100 div. in sec. & Ourrent. \\
\hline 0 & $10 \cdot 6$ & $100 \cdot 0$ \\
1 & $18 \cdot 2$ & $58 \cdot 0$ \\
2 & $26 \cdot 8$ & $40 \cdot 0$ \\
3 & $59 \cdot 0$ & $27 \cdot 0$ \\
4 & $55 \cdot 0$ & $19 \cdot 3$ \\
5 & $74 \cdot 8$ & $14 \cdot 1$ \\
6 & $104 \cdot 0$ & $10 \cdot 1$ \\
7 & $125 \cdot 6$ & $8 \cdot 0$ \\
8 & $146 \cdot 0$ & $7 \cdot 3$ \\
9 & $173 \cdot 2$ & $6 \cdot 0$ \\
10 & $183 \cdot 0$ & $5 \cdot 8$ \\
11 & $196 \cdot 6$ & $5 \cdot 4$ \\
12 & $198 \cdot 0$ & $5 \cdot 5$ \\
\hline
\end{tabular}

The results are expressed graphically in fig. 3 .

Table III. gives the result for a thin layer under similar conditions, the curve is shown in fig. 4. For convenience of comparison the maximum current in the latter case is also taken as 100; the actual current for the thin layer with no

Phil. Mag. S. 5. Vol. 48. No. 293. Oct. 1899. 
Fig. 3.-Screening effect of thin Aluminium foil.

Thorium Oxide. Thick layer.

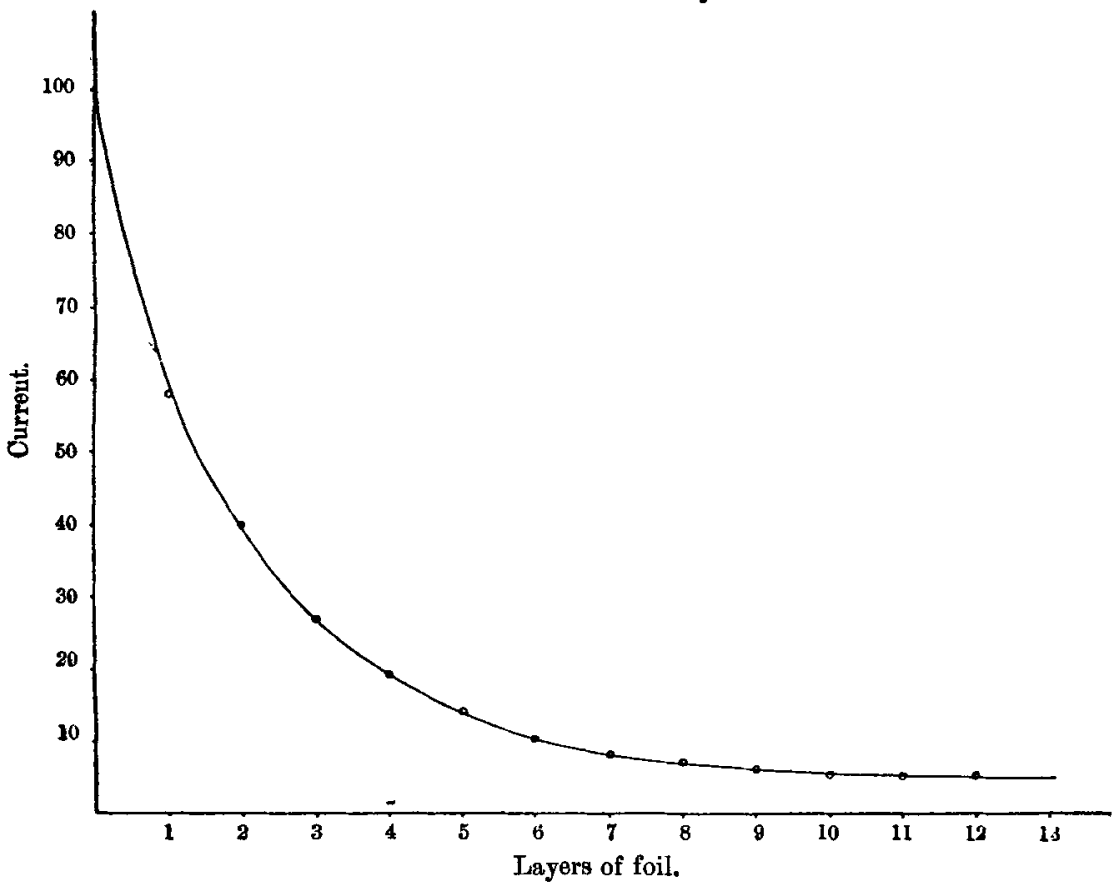

foil over its surface was about 25 per cent. of the current with thick layer, as may be seen from the tables.

TABLe III.

Thorium Oxide. Thin layer.

Screening effect of thin Aluminium foil.

Plates $5 \mathrm{~cm}$. apart. Lower plate 95 volts + .

\begin{tabular}{|c|r|r|}
\hline Layers of foil. & Time of 100 div. in sec. & Current. \\
\hline 0 & $45 \cdot 6$ & $100 \cdot 0$ \\
1 & 842 & $54 \cdot 0$ \\
2 & 1600 & $28 \cdot 5$ \\
3 & $270 \cdot 0$ & $16 \cdot 9$ \\
4 & $476 \cdot 0$ & $9 \cdot 5$ \\
5 & $881 \cdot 0$ & $5 \cdot 2$ \\
6 & $1595 \cdot 0$ & $2 \cdot 8$ \\
8 & $5640 \cdot 0$ & $0 \cdot 8$ \\
\hline
\end{tabular}


Fig. 4.-Screening effect of thin Aluminium foil. Thorium Oxide. Thin layer.

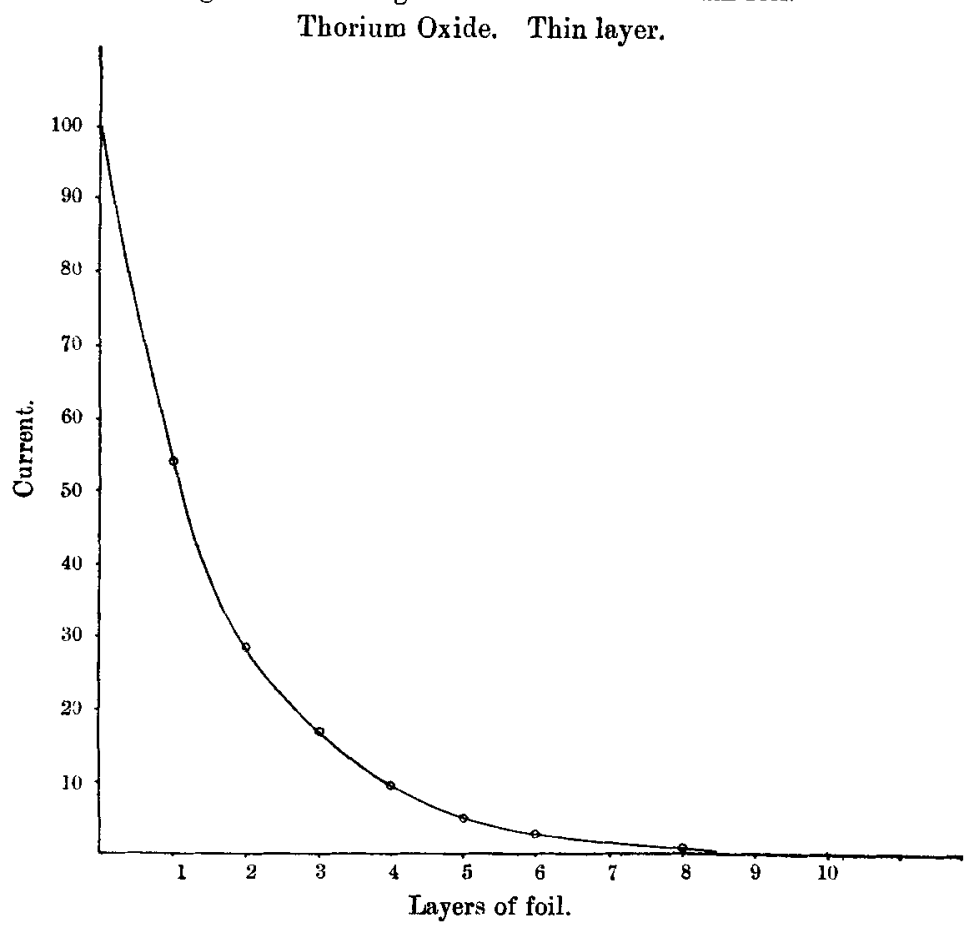

An inspection of the curve (fig. 3) at once shows that the radiation is at first absorbed rapidly, but as successive layers are added they produce a smaller and smaller proportional diminution of the current.

Evidently the radiation consists of a readily absorbable kind, forming the greater part of the whole, and a more penetrating kind small in amount as compared with the first. If the radiation is homogeneous a simple absorption law should apply, that is, the current should decrease in geometrical progression as the thickness of the absorbing layer increases in arithmetical progression, or if one of the two kinds is homogeneous the current should approximately obey the law when it is mainly due to this kind. As the first part of the curve is nearly logarithmic, we may infer that the first or more absorbable part of the radistion is nearly if not quite of one kind.

Again, if a thin layer of the active material is used, the conduction-current will be smaller and the total amount of $2 \mathrm{D} 2$ 
the more penetrating kind, though possibly remaining the same percentage of the whole, will, in actual measure, be too small to affect the electrometer. Consequently, the curve for a thin layer should much more elosely follow the usual absorption law than for a thick one, which we see by an inspection of curve, fig. 4, is actually the case. The agreement of the first part of the curve is perfect.

Consequently, the more absorbable kind may be assumed to be homogeneous at least as far as absorption phenomena indicate.

The same general method was used to investigate the nature of the more penetrating kind, but a comparatively thick aluminium sheet about 13 millim. was used instead of -0008 centim. foil. The results are given in Table IV., and shown graphieally on fig. 5 .

The curve, however, shows no approximation to representing a simple absorption law, indicating that the more penetrating radiation is complex, consisting probably of a number of component parts. In this respect it is unlike the $\beta$ radiation described by Rutherford for uranium, which he considered to be approximately homogeneous in character.

In Table V. are given the results for thorium sulphate, using thin aluminium foil to cut down the radiations. The results are plotted on fig. 6 .

Table VI. and fig. 7 give the results for the nitrate.

It will be noticed that the more penetrating radiation for both is a smaller per cent. of the total than with the oxide, and along the first part of both curves the current decreases in geometrical progression very closely as the thickness of foil increases in arithmetical progression, which is what would be expected if the more penetrating kind is small in amount and the major part homogeneous.

When ordinary foolscap-paper was used instead of the aluminium foil, very curious results were obtained. With a thick layer of the oxide the first layer of paper cut down the conduction-current about 50 per cent, the next fifteen additional layers produced practically no further diminution in its value. Fifteen more layers cut the current down to 33 per cent.

With paper a very considerable time was required for the current to come to a steady value as successive layers were added.

When a thin layer of oxide is used, the action is quite different, the absorption curve being quite regular and approximating to those obtained when aluminium foil was used.

The explanation may possibly be that the penetrating radiations from a thick layer of the oxide in passing through 
the naper causes it to give off a secondary radiation comparable in its ionizing effects to the more absorbable kind that fails to get through.

5. Selective Absorption.-The phenomenon of selective absorption has been noticed for Röntgen rays by Prof. J. J. Thomson, and is discussed by Sagnac * in a recent issue of the Journal de Plysique. The latter finds that the intensity of the rays, after passing through a particular number of layers of different substances, both as measured electrically and by the action of the rays on a photographic plate, varies with the order of the layers.

\section{TABLE IV.}

Thorium Oxide. Thick layer.

Screening effect of thick Aluminium foil.

Plates $5 \mathrm{~cm}$. apart. Lower plate 95 volts + .

\begin{tabular}{|c|c|c|}
\hline Layers of foil. & Time of 100 div. in sec. & Current. \\
\hline 0 & 160 & \\
\hline 1 & 1870 & $100 \cdot 0$ \\
2 & 2000 & 93.5 \\
3 & $218 \cdot 0$ & $85 \cdot 8$ \\
4 & $243 \cdot 0$ & $77 \cdot 0$ \\
5 & 2770 & 675 \\
\hline
\end{tabular}

Fig. 5.-Screening effect of Aluwinium sheet.

Thorium Oxide. Thick layer.

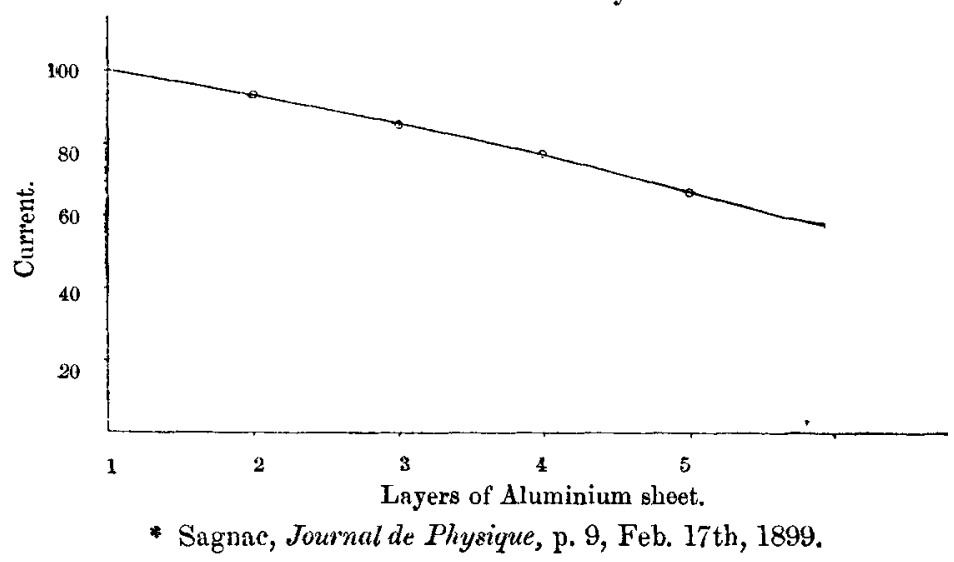


TABLE V.

Thorium Sulphate. Thick layer.

Screening effect of thin Aluminium foil.

Plates $5 \mathrm{~cm}$. apart. Lower plate 95 volts + .

\begin{tabular}{|c|c|c|}
\hline Layers of foil. & Time of 100 dir. in sec. & Current. \\
\hline 0 & $72 \cdot 6$ & $100 \cdot 0$ \\
1 & $130 \cdot 8$ & $55 \cdot 0$ \\
2 & $220 \cdot 0$ & $32 \cdot 0$ \\
3 & $343 \cdot 0$ & $21 \cdot 0$ \\
4 & $518 \cdot 0$ & $14 \cdot 4$ \\
5 & $767 \cdot 0$ & $9 \cdot 5$ \\
6 & $1000 \cdot 0$ & $7 \cdot 3$ \\
8 & $1420 \cdot 0$ & $5 \cdot 1$ \\
12 & $1850 \cdot 0$ & $3 \cdot 9$ \\
\hline
\end{tabular}

Fig. 6.-Screening effect of thin Aluminium foil. Thorium Sulphate. Thick Inyer.

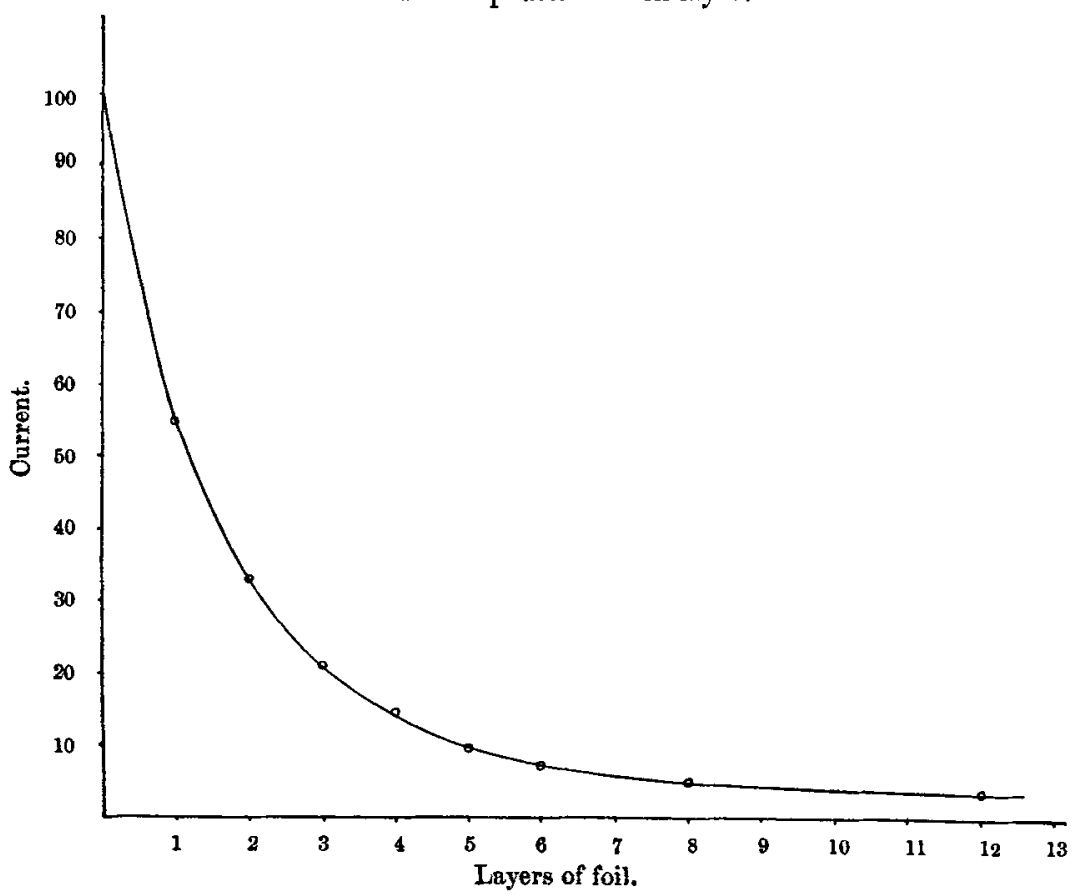


Table VI.

Thorium Nitrate. Thick layer.

Screening effect of thin Aluminium foil.

Plates $5 \mathrm{~cm}$. apart. Lower plate 95 volts + .

\begin{tabular}{|c|r|r|}
\hline Layers of foil. & Time of 100 div. in sec. & Current. \\
\hline 0 & $62 \cdot 4$ & $100 \cdot 0$ \\
1 & $107 \cdot 4$ & $58 \cdot 0$ \\
2 & $183 \cdot 2$ & $34 \cdot 0$ \\
3 & $284 \cdot 6$ & $22 \cdot 0$ \\
4 & $429 \cdot 0$ & $14 \cdot 5$ \\
5 & $642 \cdot 0$ & $9 \cdot 7$ \\
6 & $899 \cdot 0$ & $7 \cdot 0$ \\
8 & $1220 \cdot 0$ & $5 \cdot 0$ \\
12 & $1493 \cdot 0$ & $4 \cdot 1$ \\
\hline
\end{tabular}

Fig. 7.-Screening effect of thin Aluminium foll.

Thorium Nitrate. Thick layer.

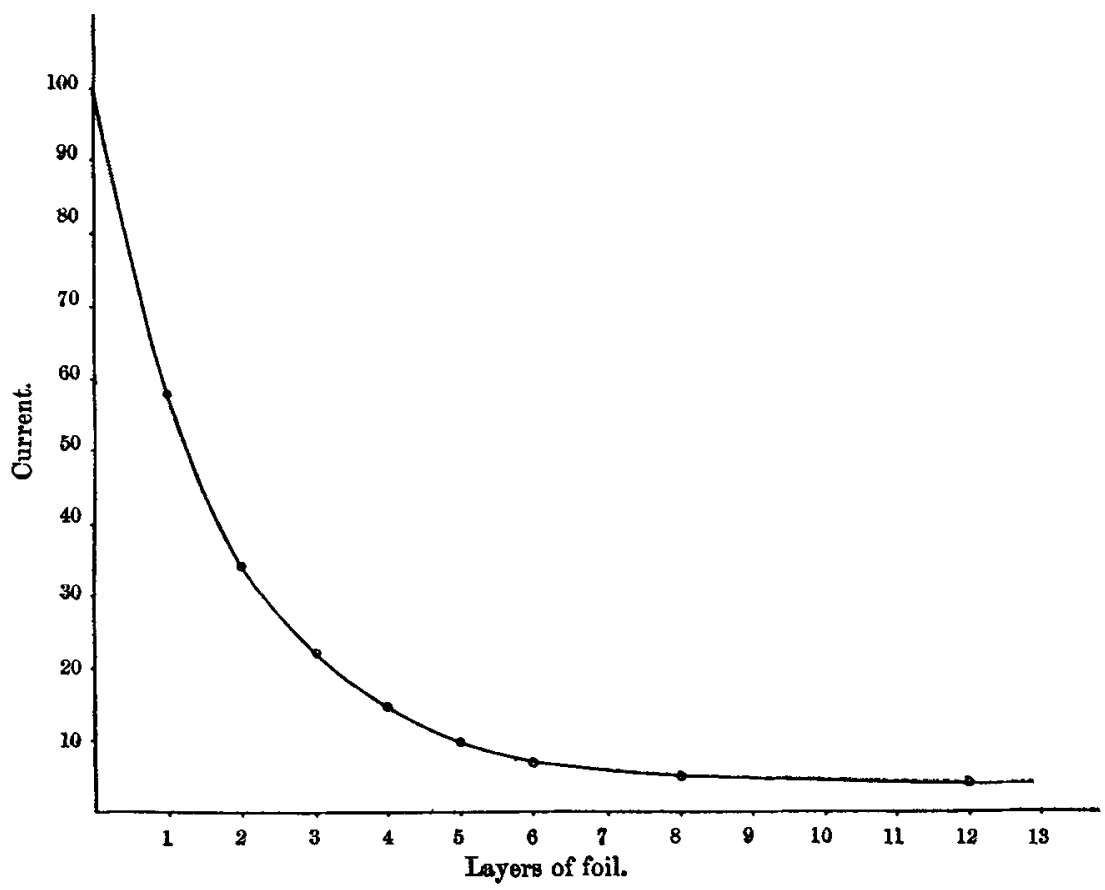


A similar phenomenon was observed with thorium radiation. Placing over a thick layer of thorium oxide a layer of paper and on the paper a layer of aluminium foil, a certain conduction-current was obtained; on reversing the layers the current was reduced to nearly one half. A number of other combinations were tried which also showed the effect in a marked manner.

6. Effect of Suspended Particles in the Path of the Conduction-Current. - A thick layer of thorium oxide covered with one layer of aluminium foil was placed on the lower plate in fig. 1, and the conduction-current measured when it had become constant.

The enclosing box was then filled with tobacco-smoke and the current again measured, and found to be about one quarter of its former value. A similar result was obtained when the sulphate was used instead of the oxide. As the smoke gradually settled or disappeared, the current steadily rose to its first value. The ions in their passage between the plates giving up their charges to the smoke particles encountered would explain the observed diminution of current.

7. Variation of Conduction-Current with Pressure of Gas. - The relation of conduction-current to pressure has been studied for Röntgen rays by Perrin*, and for uranium radiation by Becquerel $\dagger$, de Smolan and Beattie $\ddagger$, and Rutherford $\S$.

In general, the results show that the relation varies with the potential gradient between the plates and the kind and density of gas in which the radiations are absorbed. The current at any particular distance from the active material depends upon the number of ions produced in the gas up to that point, the number which have recombined in the same distance, and the electromotive force acting.

If the volume ionization were uniform and so small as not to appreciably affect the electrostatic intensity between the plates, then, as the motion of translation of the ion under the action of the electromotive force is small as compared with its motion of agitation, the current should vary directly as the potential gradient up to a point where the ionic velocity is such that practically all the ions travel from plate to plate before recombination takes place. After this the current should remain constant.

But if the volume ionization is not uniform, or is sufficient to

* Comptes Rendus, cxxiii. p. 878.

+ Ibid. p. 438 (1897).

F Phil. Mag. xliii. p. 418 (1897).

\$ Ibid. Jan. 1899 . 
disturb the original electrostatic field, then the relation between the current and electromotive force becomes more complicated. Under the latter conditions, which are probably nearer the truth than the simpler supposition first made, the observed continuous though slight rise of current with voltage beyond the "knee" of the saturation curve, the gas pressure being constant, can be explained. A certain part of the rise of current beyond the knee when parallel plates are used must of course be attributed to a lack of definite cross-section of the conducting gas; but the same thing differing only in anount has been olserved when concentric cylinders are used. A better arrangement would prokably be concentric spheres.

The number of ions produced in a given volume of a particular gas by the radiations from an active substance is known to vary as the intensity of the radiation and as the density of the absorbing gas. If the intensity of radiation is constant, the number produced and the current for a constant potential gradient will increase with the gas-density up to a certain point. If beyond this point the gas pressure is further increased, recombination becoming more and more active, the current should gradually decrease; and this has been found to be the case not only with thorium, but with other radioactive materials as well. For similar reasons, if the intensity of radiation, potential gradient, and gas density are maintained constant, the current should at first rise and then fall as the distance between the plates is continuously increased from a sufficiently small quantity. This also has been found to be the case.

For studying the relation of the conduction-current to the pressure and density of the gas in which the radiations are absorbed, the apparatus shown in fig. 8 was used. $\mathrm{A}$ is a short steel cylinder 5 in. in diameter and 6 in. long. The lower end is closed by a stout iron cap fitted tightly in place. On the upper end is screwed a cominon fitter's flange, to which is bolted the lid or cover $\mathrm{C}$, suitable packing being placed between the two to make a tight joint. $\mathrm{P}_{1}$ and $\mathrm{P}_{2}$ are small pipes screwed through the cover and attached, one to a pressure-gauge and one to an exhaust- or pressure-pump. $B_{1}$ is a removable plate to hold the active material ; $B_{2}$ is an insulated parallel plate $11 \mathrm{~cm}$. in diameter connected through the graduated rod $\mathrm{R}$ to the electrometer; the rod is insulated by a tight ebonite and rubber joint where it passes through the cover.

Using a thick layer of thorium oxide on the lower plate, and varying the pressure from $60 \mathrm{~mm}$. to nearly $2800 \mathrm{~mm}$. of mercury, the results given in Table VII. and plotted on 
fig. 9 were obtained. The plates were $1 \mathrm{~cm}$. apart, and the lower plate charged to 95 volts. The current at atmospheric pressure was taken as 100 . It will be seen that the current

Fig. 8.
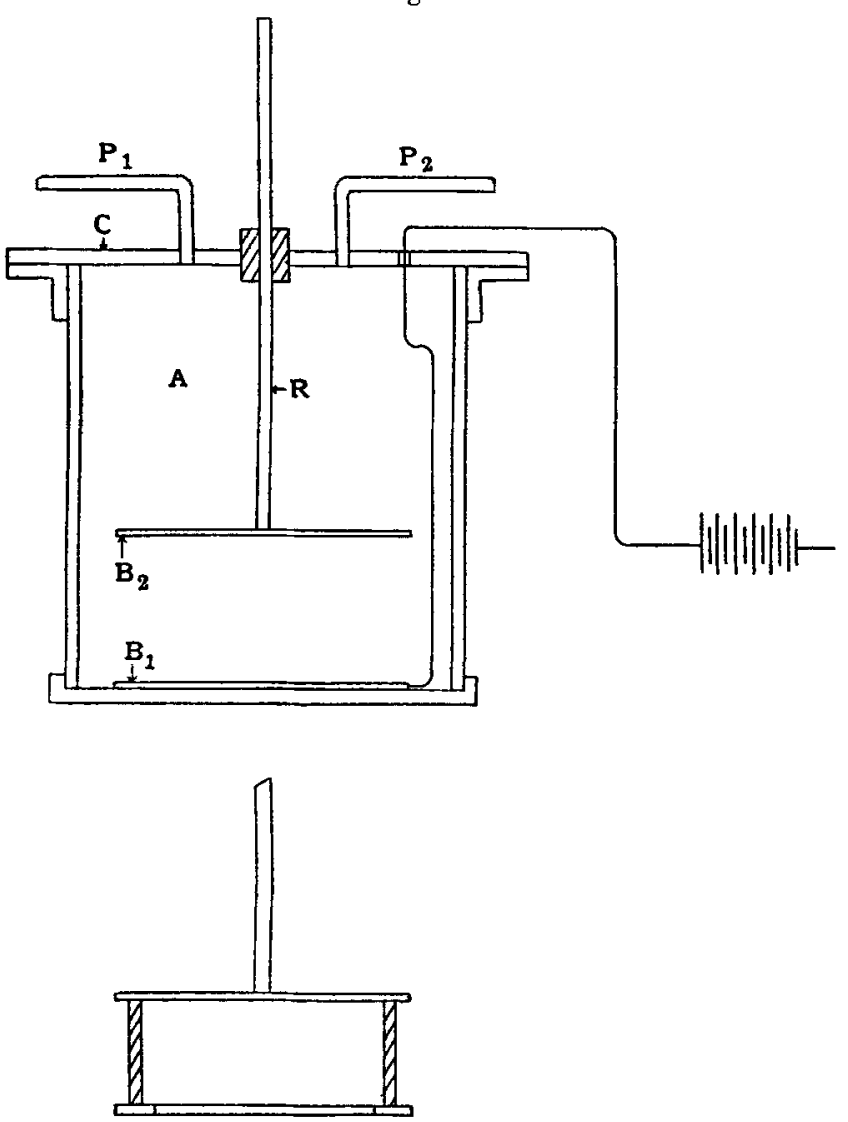

increased directly with pressure up to about $300 \mathrm{~mm}$., reached a maximum at about $600 \mathrm{~mm}$., and gradually diminished to about one-third of its maximum value at a pressure of $2786^{\circ} \mathrm{mm}$.

The result is quite in agreement with what the general considerations above indicate.

The effect of varying the distance between the plates, as well as the gas-pressure, is shown in Tables VIII $a$, VIII $b$, and VIII $c$, and on fig. 10. Pressures above an atmosphere 
only were used, and are given in pounds per square inch. The current at atmospheric pressure in each case is taken as 100. An inspection of the curves at once shows that as the distance between the plates is diminished, a greater and greater pressure must be used before the current begins to

\section{TABLE VII.}

Thorium Oxide. Thick layer.

Conduction-current with Pressure.

\section{Plates $1 \mathrm{~cm}$. apart. Lower plate 95 volts + .}

\begin{tabular}{|c|c|c|}
\hline Pressure in mm. Hg. & Time of 100 div. in sec. & Current. \\
\hline 60 & $134 \cdot 0$ & $16 \cdot 0$ \\
105 & $111 \cdot 0$ & $20 \cdot 0$ \\
155 & $53 \cdot 0$ & $41 \cdot 0$ \\
305 & $29 \cdot 0$ & $76 \cdot 0$ \\
455 & $22 \cdot 4$ & $98 \cdot 0$ \\
630 & $21 \cdot 6$ & $102 \cdot 0$ \\
760 & $22 \cdot 0$ & $100 \cdot 0$ \\
1266 & $32 \cdot 0$ & $69 \cdot 0$ \\
1813 & $42 \cdot 0$ & $52 \cdot 0$ \\
2280 & $54 \cdot 5$ & $40 \cdot 0$ \\
2786 & $74 \cdot 0$ & $30 \cdot 0$ \\
\hline
\end{tabular}

Fig. 9.-Conduction-current with Pressure.

Thorium Oxide. Thick layer. Plates $1 \mathrm{~cm}$, apart.

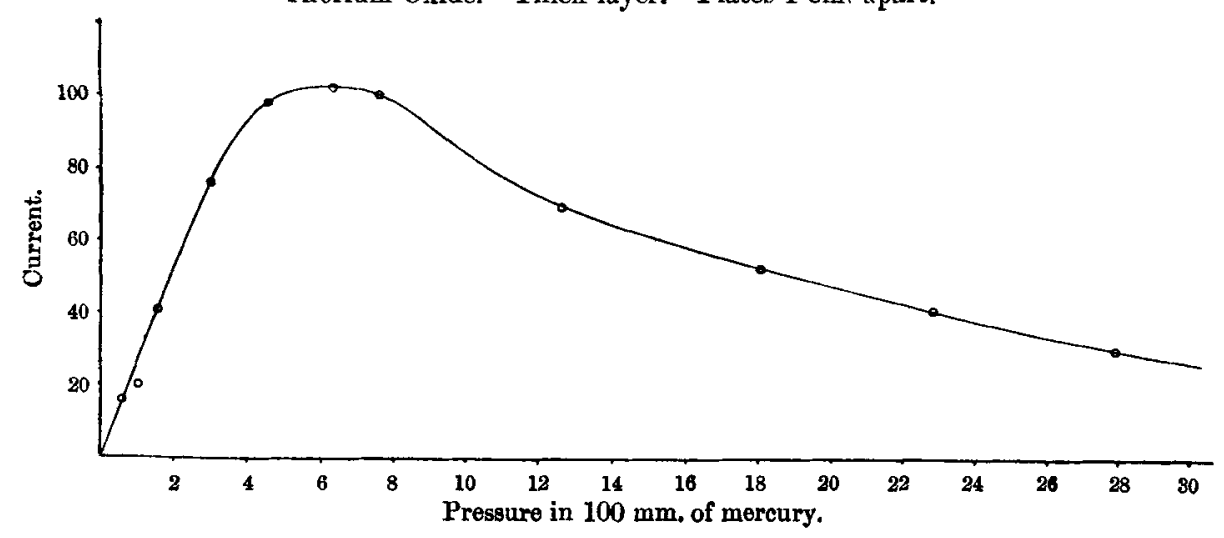


decrease as the pressure increases, and this also was to be anticipated from what has been said. Using a thick layer of uranium oxide covered with one liayer of aluminium foil, and varying the pressure from $50 \mathrm{~mm}$. to $2780 \mathrm{~mm}$. of mercury, the results as given in Table IX. and on fig. 11 were obtained. The plates were $4 \mathrm{~cm}$. apart, and the lower plate charged to 95 volts.

The curve is similar to the corresponding one for thorium.

\section{TABLE VIII $a$.}

Thorium Oxide. Thick layer.

Conduction-current with.Pressure.

Plates $2.5 \mathrm{~mm}$. apart. Lower plate 95 rolts + .

\begin{tabular}{|c|c|c|}
\hline Pressure. & Cime of 100 div. in sec. & Current. \\
\hline 15 & 88.0 & $100 \cdot 0$ \\
20 & 840 & 1050 \\
25 & $80 \cdot 4$ & $109 \cdot 0$ \\
30 & 80.8 & $109 \cdot 0$ \\
45 & $78 \cdot 6$ & $112 \cdot 0$ \\
55 & 81.0 & 109.0 \\
\hline
\end{tabular}

\section{Table VIII $b$.}

Thoriun Oxide. 'l'hick layer.

Conduction-current with Pressure.

Plates $5 \mathrm{~mm}$. apart. Lower plate 95 volts + .

\begin{tabular}{|c|c|c|}
\hline Pre-sure. & Time of 100 div. in sec. & Current. \\
\hline 15 & 645 & $100 \cdot 0$ \\
30 & 61.6 & 1050 \\
45 & 700 & $92 \cdot 0$ \\
\hline
\end{tabular}




\section{TABLE VIIT $c$.}

'Ihorium Oxide. Thick layer.

Conduction-current with Pressure.

Plates $20 \mathrm{~mm}$. apart. Lower plate 95 volts + .

\begin{tabular}{|c|c|c|}
\hline Pressure. & Time of 100 div. in sec. & Current. \\
\hline 15 & 276 & $100 \cdot 0$ \\
20 & $28 \cdot 6$ & 960 \\
25 & 316 & 870 \\
35 & $37 \cdot 4$ & 740 \\
45 & 448 & $62 \cdot 0$ \\
55 & 552 & 500 \\
\hline
\end{tabular}

Fig. 10.-Conduction-current with Pressure.

Thorium Oxide. Thick layer. I. Plates $2.5 \mathrm{~mm}$. apart.

II. Plates $5.0 \mathrm{~mm}$. apart. III. Plates $20^{\circ} 0 \mathrm{~mm}$. apart.

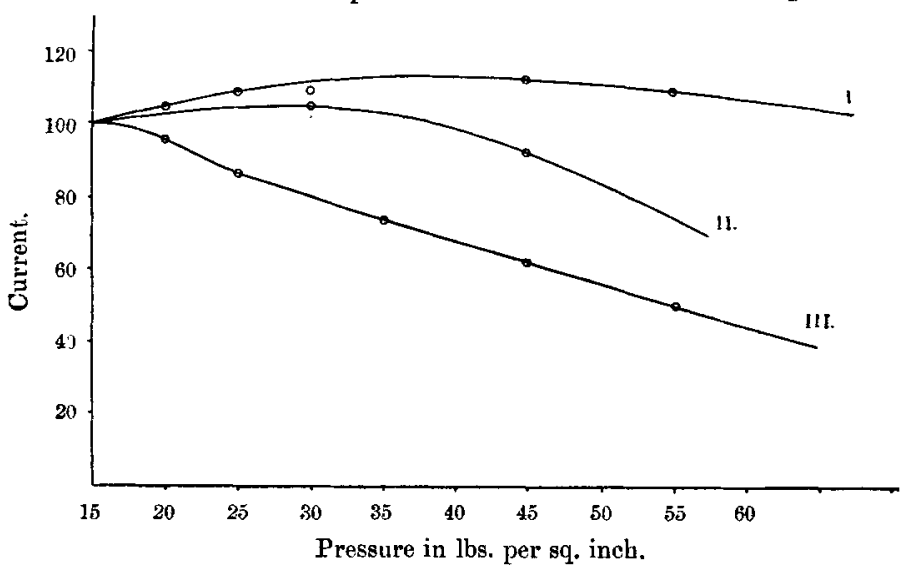

In Tables $\mathrm{X} a, \mathrm{X} b$, and $\mathrm{X} c$, and fig. 12, the relations for uranium oxide between current and pressure for different distances between plates, with pressures above an atmosphere, are given. Again we see, that as the plates are brought closer together, the pressure must be increased to make the enrve slope to the $x$-axis. 
Prof. Owens on Thorium Radiation.

TABLE IX.

Uranium Oxide. Thick layer.

Conduction-current with Pressure.

Plates $4 \mathrm{~cm}$. apart. Lower plate 95 volts + .

One layer of Aluminium foil over active material.

\begin{tabular}{|c|c|c|}
\hline Pressure in mm. Hg. & Time of 100 div. in sec. & Current. \\
\hline 45 & $94 \cdot 0$ & $22 \cdot 0$ \\
110 & $42 \cdot 0$ & $50 \cdot 0$ \\
150 & $33 \cdot 4$ & $63 \cdot 0$ \\
200 & $27 \cdot 4$ & $77 \cdot 0$ \\
255 & $25 \cdot 6$ & $8 \cdot 0$ \\
320 & $22 \cdot 4$ & $93 \cdot 5$ \\
460 & $21 \cdot 0$ & $100 \cdot 0$ \\
640 & $20 \cdot 8$ & $101 \cdot 0$ \\
760 & $21 \cdot 0$ & $100 \cdot 0$ \\
1014 & $23 \cdot 6$ & $90 \cdot 0$ \\
1266 & $26 \cdot 0$ & $80 \cdot 0$ \\
1813 & $30 \cdot 0$ & $70 \cdot 0$ \\
2332 & $33 \cdot 4$ & 660 \\
2786 & $34 \cdot 4$ & $61 \cdot 0$ \\
\hline
\end{tabular}

Fig. 11,-Conduction-current with Pressure.

Uranium Oxide. Thick layer. I sheet aluminium foil.

Plates $4 \mathrm{~cm}$. apart.

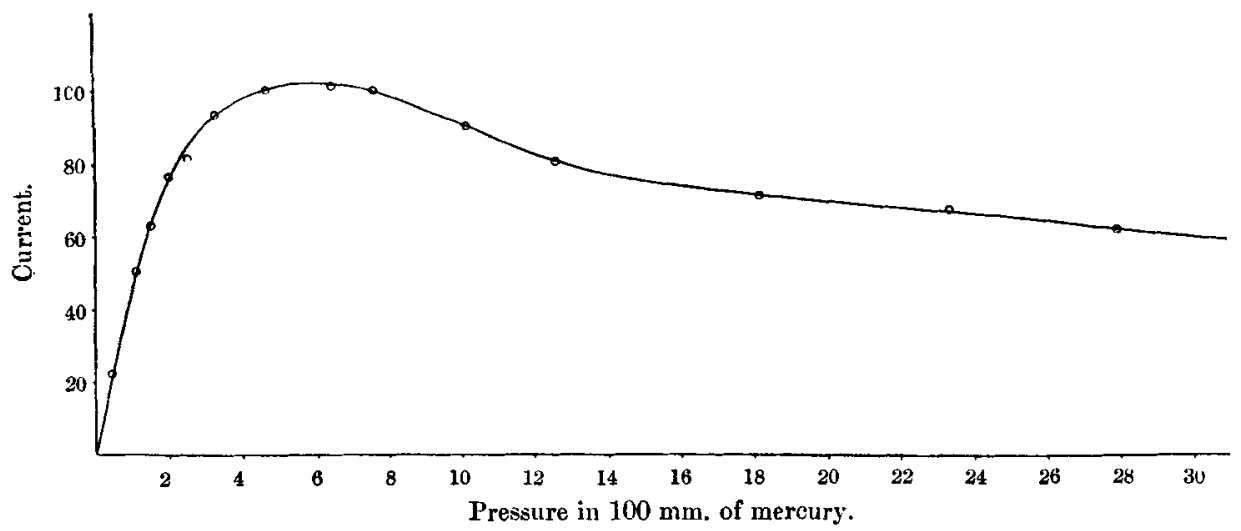


TABLE X $a$.

Uranium Oxide. Thick layer.

Conduction-current with Pressure.

Plates $2 \mathrm{~mm}$. apart. Lower plate 95 volts + .

\begin{tabular}{|c|c|c|}
\hline Pressure. & Time of 100 div. in sec. & Ourrent. \\
\hline 15 & $91 \cdot 0$ & $100 \cdot 0$ \\
20 & $73 \cdot 4$ & $122 \cdot 0$ \\
25 & $66 \cdot 4$ & $135 \cdot 0$ \\
30 & $61 \cdot 0$ & $148 \cdot 0$ \\
35 & $57 \cdot 0$ & $159 \cdot 0$ \\
45 & $53 \cdot 4$ & $168 \cdot 0$ \\
55 & $51 \cdot 4$ & $175 \cdot 0$ \\
\hline
\end{tabular}

TABLE $\mathrm{X} b$.

Uranium Oxide. Thick layer.

Conduction-current with Pressure.

Plates $6 \mathrm{~mm}$. apart. Lower plate 95 volts + .

\begin{tabular}{|c|c|c|}
\hline Pressure. & Time of 100 div. in sec. & Current. \\
\hline 15 & $60 \cdot 0$ & $100 \cdot 0$ \\
20 & $51 \cdot 4$ & $116 \cdot 0$ \\
25 & $48 \cdot 2$ & $124 \cdot 0$ \\
30 & $47 \cdot 6$ & $126 \cdot 0$ \\
35 & $48 \cdot 8$ & $123 \cdot 0$ \\
45 & 53.4 & $112 \cdot 0$ \\
55 & $60 \cdot 4$ & $99 \cdot 3$ \\
\hline
\end{tabular}

8. Absorption of Radiations in Air.-The absorption of uranium radiation in different gases under various conditions has been studied by Rutherford*. Using thin layers of the active material, so that the radiation was approximately homogeneous, he found that for different gases at a given pressure the absorption followed the order of the gas densities, and for a particular gas the absorption was proportional to the pressure.

* Phil. Mag. Jan. 1899. 
TABLE $\mathbf{X} c$.

Uranium Oxide. Thick layer.

Conduction-current with Pressure.

Plates $20 \mathrm{~mm}$. apart. Lower plate 95 volts + .

\begin{tabular}{|c|c|c|}
\hline Pressure, & Time of 100 dir. in sec. & Current. \\
\hline 15 & 198 & $101 \cdot 0$ \\
20 & 21.2 & 940 \\
25 & 234 & $84 \cdot 1$ \\
35 & 290 & 680 \\
4.5 & 354 & 560 \\
55 & $41 \cdot 2$ & $48 \cdot 0$ \\
\hline
\end{tabular}

Fig. 12.-Conduction-current with Pressure.

Uranium Oxide. I. Plates $2 \mathrm{~mm}$. apart. II. Plates $6 \mathrm{~mm}$. apart. III. Plates $30 \mathrm{~mm}$. apart.

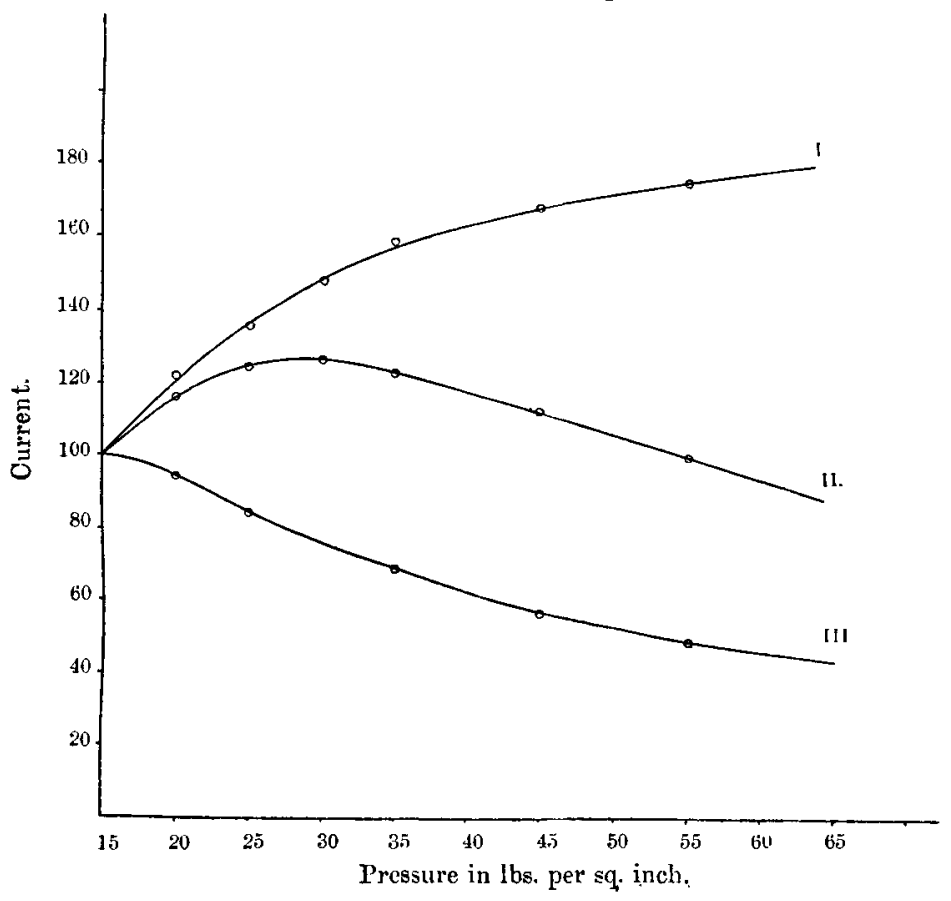


The alssorption of thorium radiation as a function of the depth of the absorbing layer of gas for air at different pressures is given below.

The method used was the same as that employed for studying the absorption by aluminium foil. The depth of the absorbing layer of air was varied by altering the distance between the active material and two insulated parallel brass plates attached to the rod $\mathrm{R}$, fig. 8 , and shown below the figure. A circular hole, $8 \mathrm{~cm}$. in diameter, was cut in the lower plate, and covered with a single layer of aluminium. foil to admit the radiations. The lower plate was connected to a battery of 95 volts. The upper plate was connected to the electrometer as usual.

Using a thick layer of thorium oxide, the relation between the conduction-current between the two plates and the distance of the lower one from the active material for pressures of $\frac{1}{2}, 1,2$, and 3 atmospheres is given in Tables XI $a$, $\mathrm{XI} l, \mathrm{XI} c, \mathrm{XI} d$, and on tig. 13 .

It will be noticed that for pressures of $\frac{1}{2}$ and 1 atmosphere the conduction-current varies inversely in geometrical progression very nearly as the distance of the lower plate from the active material increases in arithmetical progression. At higher pressures the current does not decrease with distance so rapidly, due to the fact that at high pressures the current is produced in larger part by the more penetrating kind of radiations, which are absorbed much less rapidly.

\section{TABLE XI $a$.}

Thorium Oxide. Thick layer.

Absorption of radiations in air.

Distance apart of fixed plates $3 \mathrm{~cm}$. Lower plate 95 volts + . Distance from oxide to lowest position of movable plate

$$
=d=2.25 \mathrm{~mm} \text {. }
$$

Pressure $\frac{1}{2}$ atmosphere.

\begin{tabular}{|c|c|c|}
\hline Distance in mm. & Time of 100 div. in sec. & Current. \\
\hline$d=2 \cdot 25$ & $2 \cdot 0$ & 100.0 \\
$d+10 \cdot 0$ & 31.8 & 70.0 \\
$d+20 \cdot 0$ & 46.8 & 47.0 \\
\hline
\end{tabular}

Phil. Mag. S. 5. Vol. 48. No. 293. Oct. $1899 . \quad 2 \mathrm{E}$ 
TABLE Xl $b$.

Thorium Oxide. Thick layer.

Absorption of radiation in air.

Distance apart of fixed plates $3 \mathrm{~cm}$. Lower plate 95 volts + .

Distance from oxide to lowest position of movable plate $=d=2 \cdot 25 \mathrm{~mm}$.

Pressure 1 atmosphere.

\begin{tabular}{|c|c|c|}
\hline Distance in mm. & Time of 100 div. in sec. & Current. \\
\hline$d=2 \cdot 25$ & $29 \cdot 8$ & 1000 \\
$d+5 \cdot 0$ & $41 \cdot 0$ & $72 \cdot 9$ \\
$d+10 \cdot 0$ & $59 \cdot 6$ & $50 \cdot 0$ \\
$d+15 \cdot 0$ & $85 \cdot 8$ & $34 \cdot 7$ \\
$d+20.0$ & 1200 & $24 \cdot 7$ \\
\hline
\end{tabular}

Table XI $c$.

Thorium Oxide. Thick layer.

A bsorption of radiations in air.

Distance apart of fixed plates $3 \mathrm{~cm}$. Lower plate 95 vol ts $t$.

Distance from oxide to lowest position of movable plate

$$
=d=2 \cdot 25 \mathrm{~mm} \text {. }
$$

Pressure 2 atmospheres.

\begin{tabular}{|c|c|c|}
\hline Distance in mm. & Time of 50 div. in sec. & Cirrent. \\
\hline$d=2 \cdot 25$ & $24 \cdot 4$ & $100 \cdot 0$ \\
$d+2 \cdot 5$ & $33 \cdot 0$ & $74 \cdot 0$ \\
$d+5 \cdot 0$ & $48 \cdot 4$ & $50 \cdot 0$ \\
$d+10 \cdot 0$ & 884 & $27 \cdot 4$ \\
\hline
\end{tabular}

It will also be seen, by an inspection of the curves, that the conduction-current between the two fixed plates, or, in other words, the absorption in the layer of air between the lower plate and the active material, varies very nearly as the pressure for a particular distance of the lower plate from the active material. If a thin layer of the oxide had been used the proportionality would have been closer.

My thanks are due to Prof. Rutherford, whose interest and assistance made possible the investigation. 
TABLE XId.

Thorium Oxide. Thick layer.

Absorption of radiation in air.

Distance apart of fixed plates $3 \mathrm{~cm}$. Lower plate 95 volts + .

Distance from oxide to lowest position of movable plate

$$
=d=2 \cdot 25 \mathrm{~mm} \text {. }
$$

Pressure 3 atmospheres.

\begin{tabular}{|c|c|c|}
\hline Distance in mm. & Timo of 100 div. in sec. & Current. \\
\hline$d=2 \cdot 25$ & $41 \cdot 0$ & $100 \cdot 0$ \\
$d+2 \cdot 50$ & 66.0 & $62 \cdot 0$ \\
$d+5 \cdot 0$ & 103.4 & $40 \cdot 0$ \\
$d+7.5$ & 1510 & $27 \cdot 0$ \\
\hline
\end{tabular}

Fig. 13.-Absorption Curve. Air.

Thorium Oxide. Thick layer. Fixed plates $\$ \mathrm{~mm}$. apart. I. $\frac{1}{2}$ atmosphere pressure; II. 1 atmosphere pressure; III. 2 atmospheres pressure; IV. 3 atmospheres pressure.

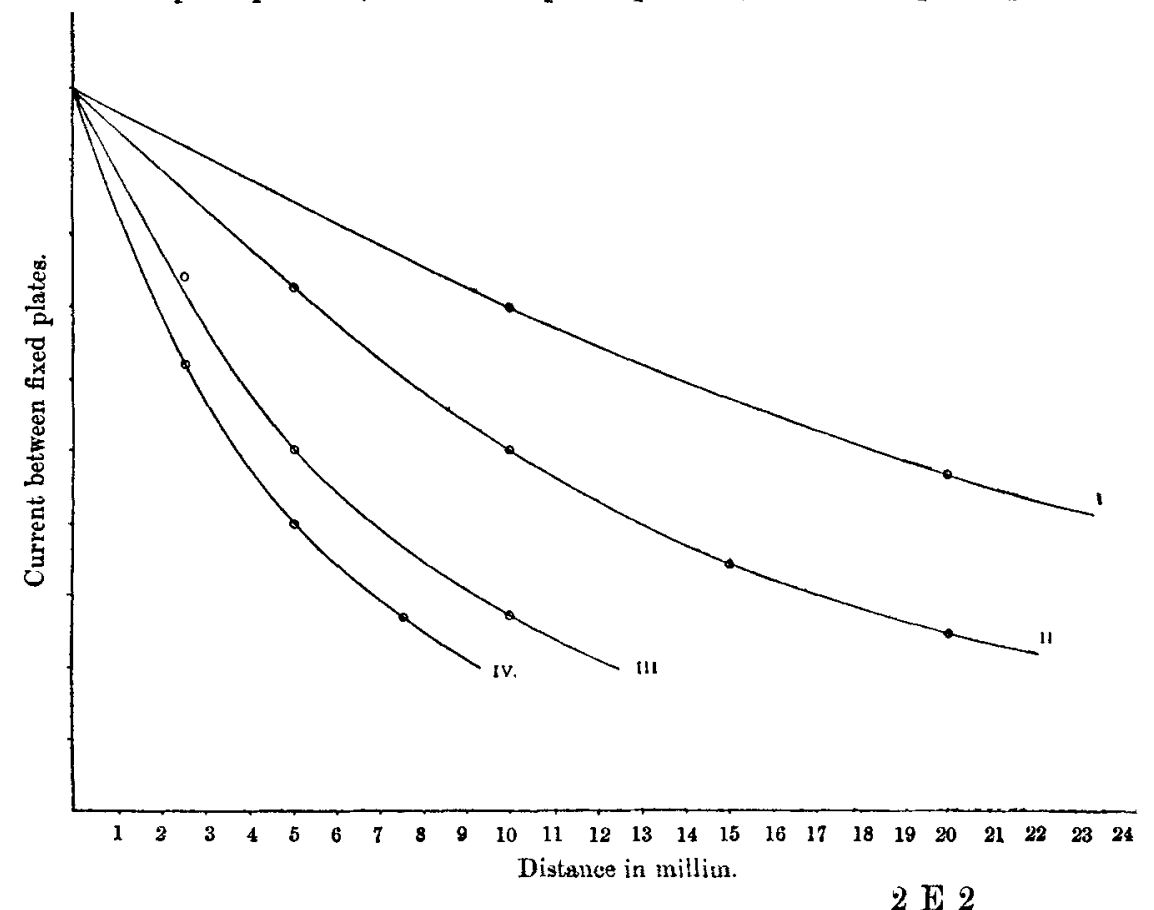

